the sea-water to a depth of several feet. Samples for examination were obtained by "dipping" with a bucket, as well as by the tow-net. It seemed to be a Confervoid Alga.

On slightly agitating the water in a glass jar, the fluffy masses broke up into minute particles, which, under a magnifying power of sixty diameters, were found to be composed of spindle-shaped bundles of filaments. Under a power of 500 diameters these filaments were seen to be straight or slightly-curved rods, articulated but not branching, and divided by transverse septa into cylindrical cells, which contained irregularly-shaped masses of granular inatter. These rods, which seemed to represent the adult plant, measured $\frac{1}{20}$ inch in width. On carefully examining many samples, some filaments were detected, portions of which seemed to have undergone a sort of varicose enlargement, being more than twice as wide as the normal filaments. These propagating filaments (if I am right in so calling them) were invested by a delicate tubular membrane, and contained some granular semi-transparent matter, in which was imbedded a row of discoid bodies; the latter appearing as if about to be discharged from the ruptured extremity of the tube. These bodies measured ${ }^{1} \frac{1}{2} \sigma_{\text {th }}$ of an inch in diameter: when seen edgewise presented a

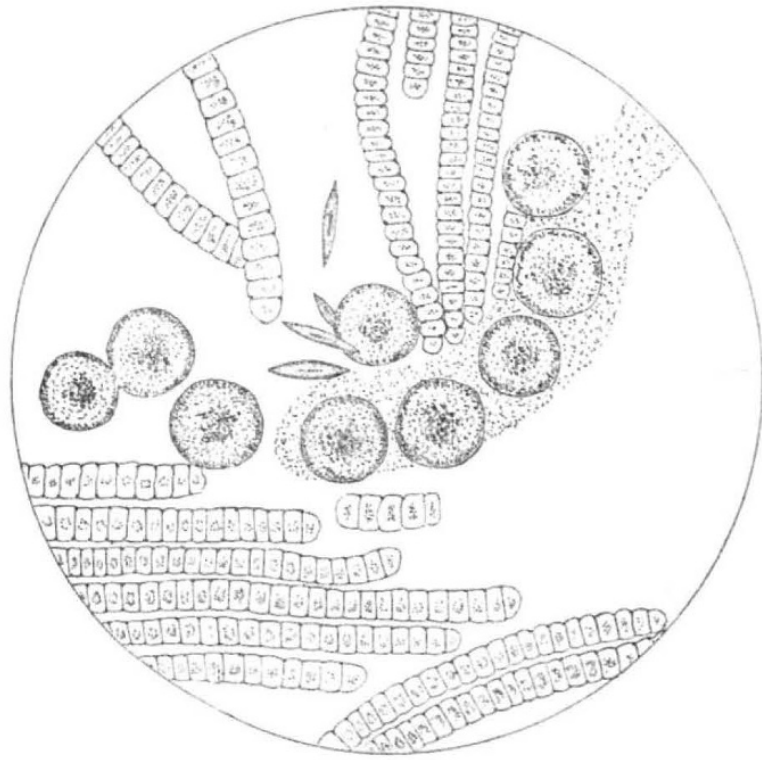

lozenge-shaped arpearance, and were devoid of cilia or striæ Conjugation was not observed.

On allowing a jarful of the sea-water to stand by for twentyfour hours it was found that the confervoid matter had all risen to the surface, forming a thick scum of a dull green colour, while the water had assumed a pale purple colour, resembling the tint exhibited in a weak solution of permanganate of potash.

From November 24 to 29 , during which time the ship traversed slowly a distance of 330 miles, the sea contained these organisms. For the first three days the large patches were frequently in sight, and during the rest of the time the surrounding water presented a dusty appearance from the presence of the tiny spindle-shaped bundles. On the evening of the 26 th an unusually dense patch was sighted and mistaken for a reef, being reported as such by the look-out-man aloft.

Sydney, Jantary 24

R. W. COPPINGER

\section{Feeding a Gull with Corn}

IN Prof. Semper's recently-published work on the "Conditions of Existence as they Affect Animal Life," a review of which from the pen of Prof. Lankester appeared in your columns a fortnight ago (vol. xxiii. p. 405), allusion is made on pp. 67,68, and elsewhere to John Hunter's celebrated experiment of feeding a gull with corn. Prof. Semper, however, seems not to have been aware of the precise nature of the result of Hunter's experiment. He says: "The English anatomist Hunter purposely fed a sea-gull for a whole year on grain, and he thus succeeded in so completely hardening the inner coat of the bird's stomach, which is naturally soft and adapted to a fish diet, that in appearance and structure it precisely resembled the hard, horny skin of the gizzard of a pigeon."

The original account, I believe, of Hunter's experiment, was published in Sir Everard Home's "Lectures on Comparative Anatomy "(vol. i. p. 27I, 18I4), and an extract from that work is appended to the description of Hunter's original preparation, still preserved in the College of Surgeons, in the descriptive catalogue of that collection (vol. v., 1833, pp. 149-50, Prep. 523). What Hunter succeeded in effecting was to very much increase the thickness of the muscular walls of the gizzard, which, as may be seen by comparing his specimen (No. 523) with that of the stomach of another gull close by, have become developed to an extent about double their usual size. There is no manifest increase in the thickness of the "inner"-or socalled "epithelial"-coat of the stomach visible in the preparation, nor do Home or Owen allude to any such feature in their descriptions. Hunter's experiment, therefore, simply comes under the numerous well-ascertained instances of the increased development, consequent on increased use, of muscle, and has no real connection with the "modifying effects of food," such as that produced in canaries by feeding them on cayenne pepper, and others cited by Semper.

Zoological Society's Gardens, N.W., March I8

\section{Dynamics of "Radiant Matter"}

As the chief object of Mr. Preston's paper under the above title in NATURE, vol, xxiii. p. $46 \mathrm{r}$, seems to be to support Le Sage's "shelter theory" for gravity, you will perhaps let me point out one objection to that theory in any form which has hitherto been deemed conclusive, and with which Mr. Preston does not deal. It is that under it gravity would not vary, as it is known to do, equally with mass, but would vary not equally.

The theory applies perhaps so long as you consider only the case of isolated atoms, but it fails entirely when applied to clusters of atoms.

Observation shows that gravity varies only with distance and with mass ; but if it were caused by any form of shelter hitherto imagined, it wculd vary also with density and with bulk in such a way that a pound of, say water, would weigh more than a pound if raised into steam, because its atoms, in loose order as steam, would give each other less shelter from the action of the kinetic æther than when in close order as water, and in such a way also that two spheres of, say iron, each weighing one pound, would weigh less than two pounds if welded into one sphere, because some atoms in the one sphere would be better sheltered than any atoms in the two spheres.

March 2I

\section{The Oldest Fossil Insects}

Mr. S. H. SCUDDER has published (Anniversary Memoirs of the Boston Society of Natural History, I88o, pp. 4I, plate I) a memoir on the Devonian Insects of New Brunswick. The fragments of the six described species were discovered by the late Prof. C. F. Hartt in 1862 , and have been since 1865 described in several papers by the same author. The new paper is a very detailed and elaborate one, with entirely new and improved figures, and is followed by a number of conclusions, as the final result of his work (Report, Amer. Journ. of Sci., Feb. I88I). The conclusions would be of prominent importance for the history of the evolution of insects, if they could be accepted without reserve. Of course facts and conclusions should be able to stand the most severe test; and that is not the case with this publication. "As the simpler Devonian insects have certain special relations," he says, "with the Ephemeridæ, their description is preceded by an account of the wing-structure of the modern Mayflies as a basis of comparison" (p. 4).

The simple fact that not one of the described species has any relationship to the Ephemeridæ is sufficient to cause us to object to his descriptions and conclusions related to this family. This statement is not based upon a difference of opinion, but simply on the evidence of facts which cannot be denied by any one conversant with the families Ephemeridæ and Odonata.

Platephemera antiqua is a part of the apical half of the wing, without the tip, of a gigantic dragonfly. The suddenly narrowed second cubital space is to be found in Isophlebia of the Solenhofen slate. The imperfectness of the fragment allows no further conclusions.

Gerephemera simplex is a diagonal fragment of the middle ot 